\title{
Sex-Specific Programming of Offspring Emotionality after Stress Early in Pregnancy
}

\author{
Bridget R. Mueller and Tracy L. Bale \\ Department of Animal Biology, School of Veterinary Medicine, University of Pennsylvania, Philadelphia, Pennsylvania 19104
}

Prenatal stress is associated with an increased vulnerability to neurodevelopmental disorders, including autism and schizophrenia. To determine the critical time window when fetal antecedents may induce a disease predisposition, we examined behavioral responses in offspring exposed to stress during early, mid, and late gestation. We found that male offspring exposed to stress early in gestation displayed maladaptive behavioral stress responsivity, anhedonia, and an increased sensitivity to selective serotonin reuptake inhibitor treatment. Long-term alterations in central corticotropin-releasing factor (CRF) and glucocorticoid receptor (GR) expression, as well as increased hypothalamic-pituitary-adrenal (HPA) axis responsivity, were present in these mice and likely contributed to an elevated stress sensitivity. Changes in CRF and GR gene methylation correlated with altered gene expression, providing important evidence of epigenetic programming during early prenatal stress. In addition, we found the core mechanism underlying male vulnerability may involve sex-specific placenta responsivity, where stress early in pregnancy significantly increased expression of PPAR $\alpha$ (peroxisome proliferator-activated receptor $\alpha$ ), IGFBP-1 (insulin-like growth factor binding protein 1), HIF3 $\alpha$ (hypoxia-inducible factor 3a), and GLUT4 (glucose transporter 4) in male placentas but not females. Examination of placental epigenetic machinery revealed basal sex differences, providing further evidence that sex-specific programming begins very early in pregnancy, and may contribute to the timing and vulnerability of the developing fetus to maternal perturbations. Overall, these results indicate that stress experience early in pregnancy may contribute to male neurodevelopmental disorders through impacts on placental function and fetal development.

Key words: placenta; neurodevelopment; DNA methylation; prenatal stress; depression; affective disorders

\section{Introduction}

Stress experience during gestation is associated with an increased incidence of numerous neuropsychiatric disorders, including depression, anxiety, schizophrenia, and autism (Koenig et al., 2002; Nestler et al., 2002; Gillott and Standen, 2007; Walker et al., 2008). The mechanism through which fetal antecedents contribute to disease development is not known but likely involves a complex interaction between environment and genetics. Because many of the diseases associated with prenatal stress (PS) exhibit a sex bias in presentation, determining how sex-specific susceptibility arises may provide critical mechanistic insight, leading to the identification of novel targets for therapeutic development.

Although prenatal stress has been broadly associated with offspring disease, the developing nervous system is unlikely to show uniform vulnerability to perturbations over the course of gestation. We have recently established that the influence of prenatal stress on hippocampal dependent learning and memory was specific to the timing of stress exposure and sex of the offspring (Mueller and Bale, 2006, 2007). In addition, a recent study re-

Received April 3, 2008; revised June 30, 2008; accepted July 23, 2008.

This work was supported by the University of Pennsylvania Research Foundation and March of Dimes 5FY03-133. B.R.M. was supported by the National Institutes of Health Behavioral/Cognitive Neuroscience Training Grant T32 MH-017168. We thank K. Carlin and C. Welle for technical support and D. Pankevich for editorial assistance.

Correspondence should be addressed to Dr. Tracy L. Bale, 201ESchool of Veterinary Medicine, 3800 Spruce Street, University of Pennsylvania, Philadelphia, PA 19104. E-mail: tbale@vet.upenn.edu.

D0I:10.1523/JNEUROSCI.1424-08.2008

Copyright $\odot 2008$ Society for Neuroscience $\quad$ 0270-6474/08/289055-11\$15.00/0 vealed an association between maternal stress experience during the first trimester and an increased risk of schizophrenia in males (Khashan et al., 2008). Therefore, we hypothesized that temporal specificity may contribute to the increased incidence of disease in males exposed to prenatal stress.

Although the specific mechanism whereby maternal stress contributes to disease risk remains unclear, several key contributors have been suggested involving changes in the maternal hormonal milieu. Elevated glucocorticoids in utero can alter early life “programming" (Seckl, 2000; Meaney, 2004). However, the placenta inactivates a significant percentage of maternal glucocorticoids via $11 \beta$ HSD2 ( $11 \beta$-hydroxysteroid dehydrogenase type 2 ), protecting the fetus through the late stages of pregnancy (Seckl and Meaney, 2004). Despite the placenta's critical role in regulating the exchange of hormones, nutrients, and waste products between the maternal and fetal circulatory systems, very little is known regarding either the effects of maternal stress or the influence of fetal sex on placental function.

One potential mechanism whereby stress can influence fetal development and programming is through epigenetics, including DNA methylation (Seckl and Meaney, 2004; Weaver et al., 2004b; Tsankova et al., 2007). Although recent emphasis has been placed on the involvement of epigenetic machinery in the programming of early life events, the influence of fetal antecedents on the epigenome remains unknown (Meaney et al., 2007). Central stress components, corticotropin-releasing factor (CRF) and the glucocorticoid receptor (GR), have been previously shown to be 
regulated by methylation and programmed early in life (Weaver et al., 2004b; McGill et al., 2006). Serotonin (5-HT) neurotransmission and disease development are associated with stress pathway dysregulation (Valentino and Curtis, 1991; Nestler et al., 2002). As such, we hypothesized that fetal antecedant-mediated alterations in programming of these circuits may be an underlying factor in neurodevelopmental disorders.

\section{Materials and Methods Animals}

Mice used in these studies were on a mixed C57BL/6:129 background. Virgin female mice $(n=62)$ were mated at $6-8$ weeks of age. Presence of a copulation plug denoted gestation day 1 . The pregnant female was individually housed, given a cotton nestlet, and assigned to a stress treatment group (see below).

All mice were housed under a $12 \mathrm{~h}$ light/dark cycle (lights on at 7:00 A.M.) with ambient temperature of $22^{\circ} \mathrm{C}$ and relative humidity of $42 \%$. Food (Purina Rodent Chow; $28.1 \%$ protein, $59.8 \%$ carbohydrate, $12.1 \%$ fat) and water was provided throughout the study ad libitum. All studies were done according to experimental protocols approved by the University of Pennsylvania Institutional Animal Care and Use Committee.

\section{Prenatal stress}

Administration of chronic, variable stress was performed as previously described (Mueller and Bale, 2006). Briefly, dams were randomly assigned to treatment groups to receive stress during one of the 3 weeks, or to a control (Ctrl) nonstressed group. Pregnant mice assigned to the stress groups experienced a different stressor on each of $7 \mathrm{~d}$ during early (days 1-7), mid (days 8-14), or late (days 15-21) gestation. Chronic variable stressors included the following: $36 \mathrm{~h}$ of constant light, $15 \mathrm{~min}$ (beginning at 10:00 A.M.) of fox odor exposure (1:5000 2,4,5-trimethylthiazole; Acros Organics) exposure, novel object (eight marbles of similar shape and color) exposure overnight, 5 min of restraint stress (beginning at 10:00 A.M.) in a $50 \mathrm{ml}$ conical tube, novel noise (White Noise/Nature Sound-Sleep Machine; Brookstone) overnight, multiple cage changes throughout the light cycle, and saturated bedding $\left(700 \mathrm{ml}, 23^{\circ} \mathrm{C}\right.$ water $)$ overnight. These mild stressors were selected to be nonhabituating and for not inducing pain or directly influencing maternal food intake or weight gain (Mueller and Bale, 2006).

\section{Establishment of sex and temporal specificity of prenatal stress on behavioral stress coping responses}

\section{Offspring}

To examine the sex and gestational timing vulnerability to the influence of prenatal stress, we compared the behavioral stress response of male and female adult offspring that were exposed to maternal stress during early, mid, and late gestation. At birth, litters were culled to eight pups, and litters containing fewer than six pups were excluded from analysis. During postnatal week 4 (postnatal days 25-27) pups were weaned, group housed with same sex littermates, and ear-tagged to provide a method of permanent identification. From 10-16 weeks of age, one to two males and one to two females per litter were tested in behavioral assays of emotionality. The performance of same-sex siblings was averaged to avoid litter effects (male control $=5$ animals/4 litters; female control $=4$ animals $/ 4$ litters; male early stress $=8$ animals $/ 6$ litters; female early stress $=7$ animals $/ 6$ litters; male mid stress $=6$ animals $/ 4$ litters; female mid stress $=6$ animals $/ 4$ litters; male late stress $=7 / 4$ litters; female late stress $=6$ animals $/ 4$ litters). These offspring were tested in the tail suspension, forced swim, and open field tests, as described below, with a $10 \mathrm{~d}$ recovery period between tests.

\section{Behavioral analysis}

Tail suspension test. To examine maladaptive behaviors of adult offspring, mice were examined using the tail suspension test (TST) as previously described (Steru et al., 1985). Mice are secured to a suspended glass rod by adhesive tape placed $\sim 1 \mathrm{~cm}$ from the tip of the tail and are suspended $50 \mathrm{~cm}$ from the bench top within a visually isolated area.
Immobility time, defined as lack of all movement except for whisker movement and respiration, was recorded throughout a 6 min test session

Forced swim test. Mice were tested in a modified version of the forced swim test (FST) as previously described (Lucki, 1997; Cryan et al., 2005). All animals were placed in the cylinder for a preswim for 5 min on day 1 and then monitored during a 5 min test $24 \mathrm{~h}$ after the preswim (Cryan and Lucki, 2000). Time spent swimming, climbing, and immobile was determined by an investigator blind to treatment and sex. Immobility was defined as time spent still or only using righting movements to remain afloat. Swimming was defined as any movement horizontal in nature that involved at least two limbs. Climbing was defined as any vertical movement in which the bottom of the front paws touched the sides of the cylinder.

Open field test. Mice were exposed to the open field test during the dark cycle 1 week after completion of the FST to determine the effect of PS on anxiety-like behavior and locomotor activity. The open field apparatus consisted of a white Plexiglas box $50 \times 50 \times 22 \mathrm{~cm}$ with $1612 \times 12 \mathrm{~cm}$ squares drawn on the floor. Testing was conducted with 120 lux in the center of the box, 2-4 h after lights out (9:00 to 11:00 P.M.). Each mouse was placed in the center of the box to initiate the $5 \mathrm{~min}$ test. Mice were scored for total line crossings and center crosses by an investigator blind to treatment group. Because treatment with anxiolytic drugs increases crosses into center squares, performance in the open field test is a validated measure of anxiety-like behavior (Bale et al., 2000).

\section{Mechanistic determination of the influence of early prenatal stress on male offspring}

Because male offspring stressed early in gestation showed a significant increase in maladaptive behaviors in the TST and FST, we examined anhedonic sensitivity in a sucrose preference test. To assess possible mechanisms contributing to these sex-specific long-term outcomes, comparisons were made by placental PCR array and epigenetic analyses.

\section{Sucrose preference test}

Tail suspension and forced swim tests revealed that early prenatal stress (E-PS) produced a depressive-like phenotype in adult male offspring. To confirm these results, E-PS adult males were examined in a sucrose preference test, a measure of anhedonia, a core symptom of clinical depression (Moreau, 1997).

Eight-week-old E-PS and control male offspring $(n=16)$ were housed in a single cage, received standard chow ad libitum, and were initially trained to consume water in the two-bottle-choice paradigm for $3 \mathrm{~d}$ to habituate the mice to the free choice. A bottle of water was then replaced by a bottle of $1 \%$ sucrose solution during weeks 1 and 2 of sucrose access. During week 3, sucrose concentration was increased to $5 \%$. During weeks 4 and 5, concentration was increased to $10 \%$ (Weatherly and Arthur, 2006). The bottles were reversed twice weekly to control for side preference. Fluid intake was measured daily and replaced weekly. The results of sucrose consumption were expressed as a preference ratio for sucrose. Preference ratios were calculated as the percentage of the volume of sucrose consumed (per $24 \mathrm{~h}$ ) divided by the total fluid intake (per $24 \mathrm{~h}$ ). Food intake, water intake, and body weight were monitored throughout the sucrose preference test.

\section{Sucrose stress test}

At the conclusion of sucrose preference (day 36), sucrose was removed for $24 \mathrm{~h}$ in E-PS and control offspring. Sucrose intake over 2 and $24 \mathrm{~h}$ was compared between animals exposed to an acute predator odor stressor (1:5000 2,4,5-trimethylthiazole; Thermo Fisher Scientific) and animals that were left undisturbed $(n=4)$. A similar restriction-stress paradigm has been shown previously to induce binge-like behavior in rats (Hagan et al., 2003). Animals received standard chow and water ad libitum during the sucrose restriction period. Food and water intake was monitored during sucrose restriction and the $24 \mathrm{~h}$ after sucrose return. To control for restriction, a second experiment was conducted comparing 2 and $24 \mathrm{~h}$ sucrose intake between animals exposed to a 15 min restraint stress and animals that were left undisturbed $(n=4)$. These animals were killed after completion of the study. No tissue was saved. 


\section{Selective serotonin reuptake inhibitor treatment}

To determine whether the maladaptive stress responsive behaviors found in E-PS males were responsive to an acute selective serotonin reuptake inhibitor (SSRI), citalopram was injected $30 \mathrm{~min}$ before testing on the tail suspension test $(n=8)$, as described previously (Crowley et al., 2005). All mice were behaviorally naive. The drug was dissolved in $0.9 \%$ saline and injected at two doses: 2.5 and $10 \mathrm{mg} / \mathrm{kg}$ in a volume of $100 \mu \mathrm{l}$. Vehicle injection was $100 \mu \mathrm{l}$ of $0.9 \%$ saline. These animals were killed after completion of the study. No tissue was saved.

\section{Adult brain tissue collection}

To examine biochemical and molecular changes within the brain of adult males exposed to early prenatal stress, behaviorally naive E-PS and control adult male offspring were killed at 4 months of age $(n=4-5)$. Brains were removed and divided sagittally into two hemispheres. For all of our gene expression and autoradiographical analyses, tissue was obtained from or analyzed in the same hemisphere across all animals. For autoradiography and in situ hybridization studies, measurements for CRF and GR were from brain tissue sections from the left hemisphere. For realtime PCR studies, micropunches were made from tissue from the right hemisphere. For DNA methylation studies, bilateral micropunches were obtained for DNA isolation. For adult Western blot analysis, cortical tissue was taken from the right hemisphere. All brain tissue was stored at $-80^{\circ} \mathrm{C}$.

\section{5-HT transporter autoradiography}

Assessment of serotonin transporter (SERT) in E-PS and control males was performed with ${ }^{3} \mathrm{H}$-citalopram autoradiographic methods. Freshfrozen, atlas-matched brain sections were selected from control and E-PS mice $(n=4-5)$. Brain sections $(20 \mu \mathrm{m})$ were incubated in Tris buffer, $\mathrm{pH} 7.6$, at $37^{\circ} \mathrm{C}$ for $10 \mathrm{~min}$. Sections were then incubated in buffer containing ${ }^{3} \mathrm{H}$-citalopram (1.4 nm; PerkinElmer) for $1 \mathrm{~h}$ at $37^{\circ} \mathrm{C}$ and washed in cold $\left(0-4^{\circ} \mathrm{C}\right)$ incubation buffer $(2 \times 10 \mathrm{~min})$. Finally, slides were rinsed in cold deionized distilled water and dried under a stream of cold air. Brain sections were apposed to Kodak Hyperfilm (Eastman Kodak) for $21 \mathrm{~d}$. Film images representing atlas-matched tissue sections were selected for analysis. Region of interest outlines were designed for standardized analysis of dorsal hippocampus, lateral septum, and hypothalamus as determined by atlas reference (Paxinos and Franklin, 2001). Optical density was measured within each region of interest and averaged after subtracting background film density. Images were captured using a 10 bit cooled QICam digital camera (QImaging). Optical density measurements were made by IPlabs for Macintosh software (BD Biosciences/Scanalytics).

\section{Dorsal raphe TPH2, SERT, and 5-HT $T_{1 A}$ expression analysis}

Sections through the dorsal raphe -4.04 to $-4.96 \mathrm{~mm}$ caudal to bregma were cut at a thickness of $300 \mu \mathrm{m}$ (Paxinos and Franklin, 2001). The location of micropunched region corresponds to Figures $64-72$ of the Paxinos and Franklin mouse atlas. The area of the dorsal raphe was determined using the dorsal hippocampus and cerebral aqueduct as landmarks. Micropunches with a diameter of $1 \mathrm{~mm}$ were then taken using a hollow needle (Ted Pella). RNA was isolated using RNeasy (Qiagen) and was resuspended in RNase-free water and concentration measured on a spectrophotometer (Eppendorf). cDNA was transcribed using the SuperScript First-Strand Synthesis System for real-time (RT)-PCR with random primers (Invitrogen). Changes in serotonin receptor $1 \mathrm{~A}$ (5Htr1a; NM_008308.4; Mm00434106_s1), tryptophan hydroxylase (Tph2; NM_173391.2; Mm00557717_m1), and serotonin transporter (Slc6a4; NM_010484.1; Mm00439391_m1) were measured using quantitative real-time PCR and TaqMan Gene Expression Assay (Applied Biosystems). In addition, $\beta$-actin (Actb; NM_007393.3; Mm00607939_s1) was also measured for each sample as an endogenous control, and the cycle threshold was subtracted from the target threshold value. All samples and controls were prepared in duplicate wells of a 96-well plate and analyzed using the Applied Biosystems 7500 Fast RealTime PCR System. The cycle number at threshold (CT value) was used for calculations of relative amount of mRNA molecules. The CT value of each target gene was normalized by subtraction of the CT value from $\beta$-actin. This value is defined as the $\Delta \mathrm{CT}$. Relative quantitative change was calculated using the formula $2^{-(\Delta \mathrm{CT} \text { E-PS }-\Delta \mathrm{CT} \text { control })}(n=4-5)$.

\section{CRF and GR in situ hybridization}

Expression of genes important in stress neurocircuitry was measured by in situ hybridization. E-PS and control males were killed 2 weeks after the last behavior test. Brains were cut on a cryostat at $20 \mu \mathrm{m}$ coronal sections and mounted on slides (SuperFrost Plus; Thermo Fisher Scientific). Sections were postfixed in $4 \%$ paraformaldehyde and processed as previously described (Teegarden and Bale, 2007). Atlas-matched tissue was hybridized with ${ }^{5}$ S-UTP-labeled antisense GR (generous gift from Dr. Audrey Seasholtz, University of Michigan, Ann Arbor, MI) or CRF probes as previously described (Bale et al., 2000). Slides were incubated overnight at $55^{\circ} \mathrm{C}$, washed at $65^{\circ} \mathrm{C}$, dehydrated in ethanol, and air dried.

For silver grain analyses, slides were dipped in NTB liquid nuclear emulsion (Eastman Kodak) for $17 \mathrm{~d}$ (GR) and $21 \mathrm{~d}$ (CRF). Slides were developed, counterstained with hematoxylin (Thermo Fisher Scientific), and coverslipped. The level of expression was quantified by analyzing optical density using IPLab version 3.9 imaging system for Macintosh Computer (Scanalytics). Under bright-field illumination, appropriate regions of interest were drawn as determined by atlas reference (Paxinos and Franklin, 2001). Brain sections were anatomically matched before analyses. GR expression within CA1, CA2, CA3, and dentate gyrus (DG) were analyzed within the same brain section in four adjacent sections and averaged for each animal before statistical analysis $(n=4-5)$. Central nucleus of the amygdala (CeA) CRF expression was analyzed in two adjacent sections and averaged for each animal $(n=4-5)$. The same region-of-interest tool was used for each section. Background was subtracted from each density measurement by using a region just outside each tissue section. Microscopic light intensity was held constant in all analyses. Measurements were completed by an investigator blinded to treatment group $(n=4-5)$.

\section{Hypothalamic-pituitary-adrenal axis stress response}

To determine whether E-PS males showed altered hypothalamicpituitary-adrenal (HPA) axis response to stress, corticosterone levels in 10 -week-old adult male offspring $(n=6)$ after a 15 min restraint were compared. Restraint was conducted in a $50 \mathrm{ml}$ conical tube. Tail blood was collected immediately before stress start $(0 \mathrm{~min})$, immediately after the stress exposure (15 min), and 15 and $45 \mathrm{~min}$ after end of stress (30 and $60 \mathrm{~min}$, respectively). The blood collection procedure lasted $<1 \mathrm{~min}$. Samples were immediately centrifuged and stored at $-80^{\circ} \mathrm{C}$ until the assay was conducted. Corticosterone levels were determined by radioimmune assay (ICN Biomedicals). $(n=6)$. The intra-assay coefficient of variation was $<5 \%$.

\section{Analysis of DNA methylation of CRF, GR, and BDNF}

Methylation status of specific $\mathrm{CpG}$ dinucleotides within the promoter region of mouse CRF (McGill et al., 2006), GR type II (Weaver et al., $2004 \mathrm{~b}$ ), and brain-derived neurotrophic factor (BDNF) were analyzed (McGill et al., 2006) $(n=4-5)$. Genomic DNA from the hypothalamus and central nucleus of the amygdala of E-PS and control males were extracted from cell pellets with the DNeasy Tissue kit (Qiagen), according to the manufacturer's instructions. Pyrosequencing was performed by EpigenDx, as previously described (Kim et al., 2007; Liu et al., 2007). Universally methylated and unmethylated DNA samples (Millipore Bioscience Research Reagents) were used as controls in these experiments.

\section{Placenta tissue collection}

To determine placental gene expression profiles after prenatal stress, dams exposed to stress during the first $7 \mathrm{~d}$ of gestation and dams left undisturbed were killed $12 \mathrm{~d}$ after presence of copulation plug. This time point was chosen because at embryonic day 12, placenta formation is complete. Embryo tissue was saved for DNA isolation and placentas were immediately frozen in liquid nitrogen for RNA isolation. As previously described, RT-PCR using primers specific for Sry (5'-GAGTACAGGTGTGCAGCTCTA-3' and 5'-CAGCCCTACAGCCACATGAT-3') were used to identify sex of individual embryos (Zwingman et al., 1993). Thermal cycling conditions were $98^{\circ} \mathrm{C}$ for $30 \mathrm{~s} ; 54^{\circ} \mathrm{C}$ for $40 \mathrm{~s} ; 72^{\circ} \mathrm{C}$ for $50 \mathrm{~s}$ for 30 cycles. 


\section{Placenta RNA isolation}

From each litter, one placenta from a male embryo and one placenta from a female embryo were added to TRIzol reagent (Invitrogen) and briefly sonicated before total isolation with chloroform and precipitation with isopropanol. RNA was resuspended in RNase-free water and concentration measured on a spectrophotometer (Eppendorf).

\section{PCR array analysis of placental nutrient and oxygen transport gene expression}

RNA (750 ng) was transcribed to cDNA using the $\mathrm{RT}^{2}$ first strand synthesis kit (C-03; SuperArray Bioscience) and analyzed using the mouse hypoxia signaling pathway PCR array (PAMM.032; SuperArray Bioscience) and the RT ${ }^{2}$ SYBR green PCR master mix (SuperArray Bioscience). Each array consists of 84 genes known to be involved in the hypoxic response, cell differentiation, and metabolism, as well as 12 sequences to control for loading and cDNA quality [PUC18 plasmid DNA as negative control; actin, peptidylprolyl isomerase $\mathrm{A}$, and glyceraldehyde-3-phosphate dehydrogenase for loading]. The CT value was used for calculations of relative amount of mRNA molecules. The CT value of each target gene was normalized by subtraction of the CT value from average of five housekeeping genes. This value is defined as the $\Delta \mathrm{CT}$. Relative quantitative change was calculated using the formula $2^{-(\Delta \text { CT E-PS }-\Delta \text { CT control })}(n=4)$.

\section{Placental inflammation and epigenetic machinery expression analysis}

RNA (750 ng) was transcribed to cDNA using the SuperScript III FirstStrand Synthesis System reagent (Invitrogen). Changes in tumor necrosis factor- $\alpha$ (TNF $\alpha$; NM_013693.2; Mm99999068_m1), interleukin-6 (IL-6; NM_031168.1; Mm01210733_m1), DNA methyl transferase 1 (DNMT1; NM_0107883.3; Mm01151062_g1), DNA methyl transferase 3a (DNMT3a; NM_007872.4; Mm00432870_m1), and methyl-CpGbinding protein-2 (MeCP2; NM_010788.3; Mm00465017_m1) were assessed using TaqMan Gene Expression Assay (Applied Biosystems) $(n=$ $4-5$ ). In addition, $\beta$-actin (Actb; NM_007393.3; Mm00607939_s1) was measured for each sample as an endogenous control, and the cycle threshold was subtracted from the target threshold value. All samples and controls were prepared in duplicate wells of a 96-well plate and analyzed using the Applied Biosystems 7500 Fast Real-Time PCR System. Data was normalized to $\beta$-actin and analyzed by $\Delta$ CT-based fold-change calculations taken from raw threshold cycle data, as described above.

\section{Western blot analysis}

As a gross assessment of possible sex-specific changes in brain development after prenatal stress early in gestation, levels of neurofilament-1 (NF-1) were compared between E-PS and control, male and female pups on the morning (9:00 to 10:00 A.M.) of postnatal day 1 (the day on which a litter was present). One male and one female pup were killed, and the whole brain was rapidly removed and frozen. In adult offspring (4 months old), $500 \mathrm{mg}$ of tissue encompassing the right prefrontal cortex was excised with the aid of the mouse brain atlas reference (Paxinos and Franklin, 2001) (approximately bregma $4.20-3.20 \mathrm{~mm}$ ) and frozen in liquid nitrogen. Biochemical analyses were performed as described previously (Bale et al., 2003). Briefly, tissue was homogenized and protein extracted. All protein was run at $30 \mu \mathrm{g}$ per lane. Antibodies used were neurofilament-1 (150 kDa; 1:1000) (Millipore Bioscience Research Reagents) and vascular endothelial growth factor (42 kDa; 1:1000) (Santa Cruz Biotechnology). All blots were stripped and reincubated with $\beta$-actin (Sigma) to control for any transfer or sample-loading errors. Densitometric analyses were performed using IPLab (BD Biosciences/ Scanalytics). A region of interest was drawn around one band on the film, and an identical region was used to measure densities for each subsequent band on that blot. Raw data comparisons were made only within each blot.

\section{Statistical analysis}

All studies were conducted by an investigator blind to sex and PS treatment groups. To determine sex and temporal specific influence of PS, data were analyzed using two-way ANOVA for offspring sex and PS. For the sucrose preference and corticosterone studies, data were analyzed with day as a repeated-measures factor. A two-way ANOVA for PS and acute stress exposure determined significance of sucrose-stress test data. The effect of citalopram on offspring behavior in the tail suspension test was analyzed by a two-way ANOVA for PS and drug treatment. Bonferroni multiple-comparisons test was used post hoc to control for litter effects. For biochemical, molecular, and methylation studies, one male and female per litter were randomly chosen for analysis, and Fisher's PLSD post hoc test determined influence of PS. For PCR array data, genes displaying \pm 2 -fold changes were analyzed by a two-way ANOVA for sex and PS to determine main effects. A Fisher's PLSD post hoc test with a reduced $p$ value of 0.01 was used to control for multiple comparisons. Fold changes were computed relative to unstressed controls for male and female placentas. All statistical analysis was performed using StatView $\mathrm{SE}+$ (Abacus Concepts).

\section{Results}

\section{Behavioral analyses}

To determine potential temporal and sex-specific effects of PS on adult offspring depression- and anxiety-like behaviors, male and female offspring stressed during early, mid, late gestation, or unstressed controls were examined for behavioral stress responses in the TST, FST, and open field test. There was a significant main effect of PS $\left(F_{(3,33)}=3.9 ; p<0.05\right)$ (Fig. $\left.1 A\right)$ and a significant interaction between sex and PS treatment $\left(F_{(3,33)}=2.95 ; p<\right.$ $0.05)$ (Fig. 1A) on time spent immobile in the TST. Males exposed to E-PS spent significantly more time immobile compared with control males $(p<0.01)$ (Fig. $1 A)$. No significant effect of PS was evident in females $\left(F_{(3,17)}=0.8 ; p=0.49\right)$.

In the FST, there was a significant main effect of PS on time spent immobile $\left(F_{(3,26)}=5.2 ; p<0.05\right)$ and a significant interaction between PS and sex $\left(F_{(3,26)}=2.8 ; p<0.05\right)$. E-PS male offspring spent significantly more time immobile than control males $(p<0.01)$ (Fig. $1 B)$. In this test, the increased time spent immobile resulted from a significant decrease in time spent climbing $\left(F_{(3,26)}=4.25 ; p<0.01\right)$ (Fig. $1 C$ ) and a trend for decreased time spent swimming $\left(F_{(3,26)}=3.1 ; p=0.06\right.$ ) (Fig. $1 D)$, indicating a sex-specific effect of early PS on the catecholamine and serotonin neurotransmitter systems. No significant effect of PS on time spent immobile was present in female offspring $\left(F_{(3,13)}=0.7 ; p=0.51\right)$ (Fig. $\left.1 B\right)$.

Analysis of center crossings in the open field test revealed no effect of PS $\left(F_{(3,31)}=0.14 ; p=0.92\right)$ or $\operatorname{sex}\left(F_{(1,31)}=1.1 ; p=\right.$ 0.31 ) (Fig. $1 E$ ). To determine whether TST and FST results were affected by changes in locomotor ability, total line crosses during the open field test were measured. There were no significant effects of PS treatment $\left(F_{(3,31)}=0.164 ; p=0.03\right.$ ) (Fig. $\left.1 F\right)$ or sex $\left(F_{(1,31)}=1.3 ; p=0.27\right)$ (Fig. $\left.1 F\right)$.

\section{Mechanistic determination of the influence of early prenatal stress on male offspring}

Sucrose preference test

To determine whether maladaptive stress-coping behaviors displayed by E-PS males in the TST and FST reflect a depressive-like phenotype, the hedonic state of these offspring was assessed in a sucrose preference task. E-PS males displayed a decreased intake of $1 \%$ sucrose compared with control male offspring $\left(F_{(1,179)}=\right.$ $8.2 ; p<0.05$ ) (Fig. $2 A$ ). Increasing sucrose concentration to 5 or $10 \%$ ameliorated the diminished preference of E-PS males $\left(F_{(1,179)}=1.5 ; p>0.85\right)$ (Fig. $\left.2 A\right)$.

Body weight, food intake, and water consumption were monitored weekly during sucrose preference testing (Table 1). Prenatal stress did not significantly affect body weight $\left(F_{(1,168)}=3.5\right.$; 
A
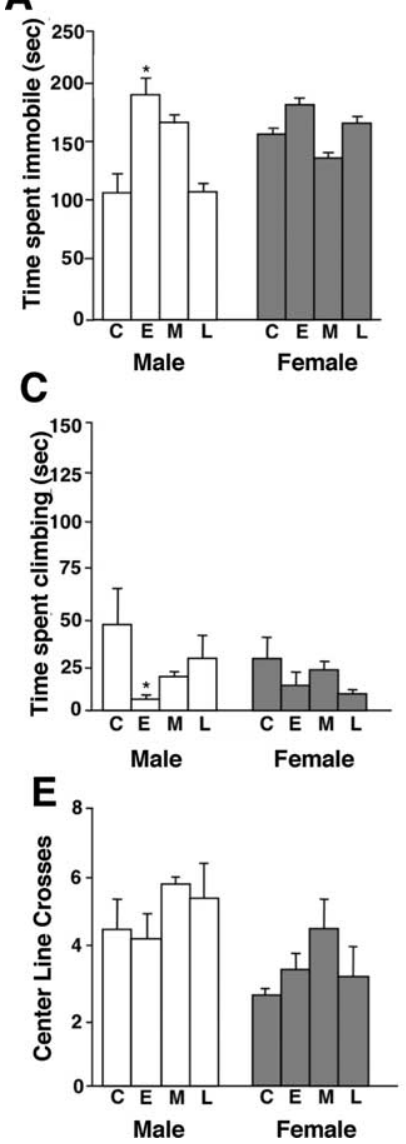

B
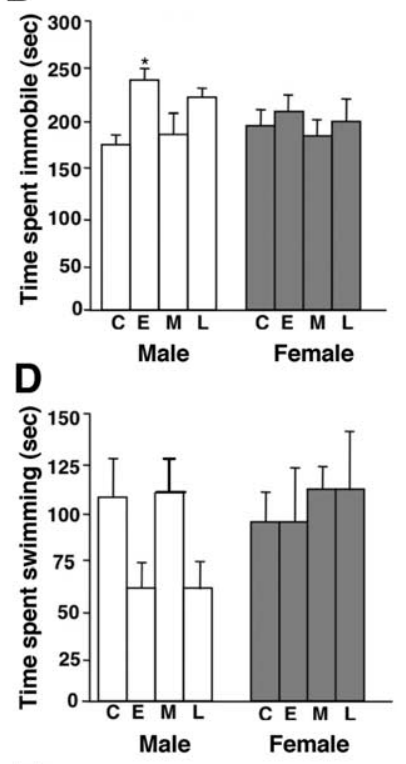

$\mathbf{F}$

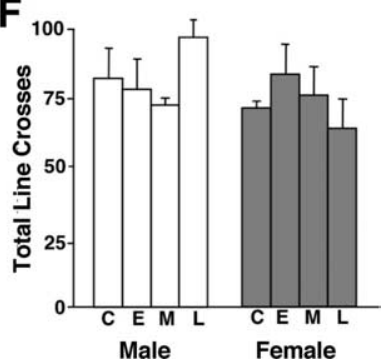

Figure 1. E-PS males showed maladaptive behavioral stress responsivity in tail suspension and forced swim tests. Male and female offspring born to unstressed dams [control (C)] or dams exposed to PS during early (E), mid (M), or late ( $\mathrm{L}$ ) gestation were compared. $\boldsymbol{A}, \boldsymbol{B}, \mathrm{E}-\mathrm{PS}$ males spent significantly more time immobile in a tail suspension test $(\boldsymbol{A})$ and a forced swim test $(\boldsymbol{B})$ compared with control males $\left({ }^{*} p<0.05\right)$. C, E-PS males spent significantly less time climbing compared with control males in the forced swim test $\left({ }^{*} p<0.05\right)$. D, No significant differences in time spent swimming were detected between control and prenatally stressed male or female offspring. $\boldsymbol{E}, \boldsymbol{F}$, No differences were found in an open field test for crosses into the center arena $(\boldsymbol{E})$ or total number of crossed lines $(\boldsymbol{F})$. Data are mean \pm SEM. $n=4-6$.

$p=0.05)$ (Table 1, top), food $\left(F_{(1,168)}=1.3 ; p>0.05\right)$ (Table 1 , middle), or water $\left(F_{(1,168)}=1.2 ; p>0.05\right)$ (Table 1 , bottom) intake. Over the 5 week period, body weights for both groups increased compared with start weights $\left(F_{(5,168)}=13.5 ; p<0.05\right)$ (Table 1, top), whereas food $\left(F_{(5,168)}=18.5 ; p<0.05\right)$ (Table 1 , middle) and water $\left(F_{(5,168)}=2.4 ; p<0.05\right)$ (Table 1 , bottom) intake decreased.

\section{Sucrose stress test}

To assess the effect of E-PS and acute stress on reward seeking behavior, sucrose was removed for $24 \mathrm{~h}$. Mice were exposed to an acute stressor or left undisturbed before sucrose return. Sucrose intake was measured over 2 and $24 \mathrm{~h}$. There was a significant main effect of acute stress exposure $\left(F_{(1,27)}=13.2 ; p<0.05\right)$ (Fig. $2 B)$ and an interaction between E-PS and acute stress exposure on $2 \mathrm{~h}$ sucrose intake $\left(F_{(1,27)}=5.3 ; p<0.05\right)$ (Fig. $\left.2 B\right)$ and $24 \mathrm{~h}$ intake $\left(F_{(1,27)}=4.1 ; p<0.05\right)$ (Fig. $2 C$ ) after overnight sucrose restriction. During the $2 \mathrm{~h}$ after acute stress, E-PS males consumed significantly more sucrose than control males $(p<0.05)$ (Fig. $2 B$ ) and undisturbed E-PS males $(p<0.05)$ (Fig. $2 B$ ). Over $24 \mathrm{~h}$, intake of stress exposed E-PS males remained significantly elevated compared with controls $(p<0.05)$ (Fig. $2 C)$.
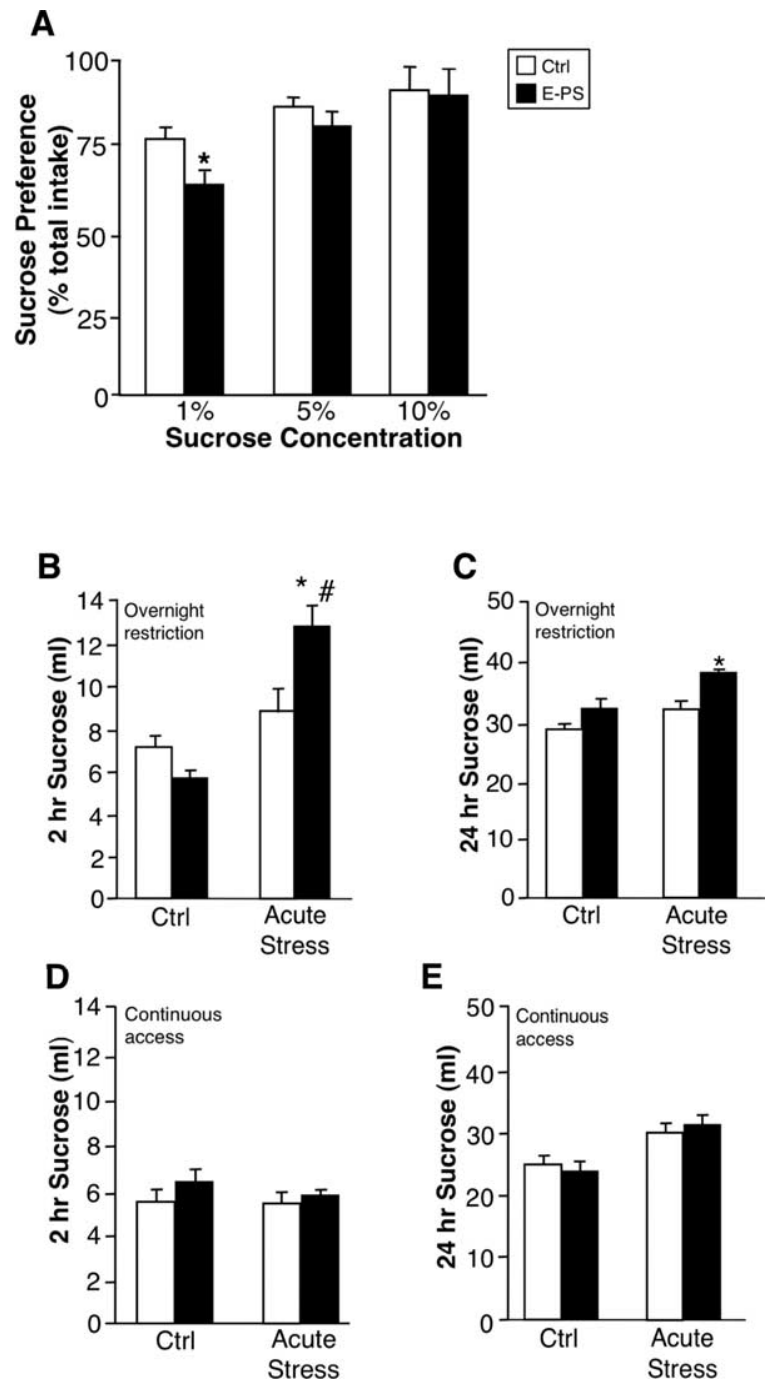

Figure 2. E-PS males showed decreased basal hedonic behavior and increased stressinduced sucrose bingeing. Anhedonia of E-PS males was examined in a sucrose preference test. $\boldsymbol{A}, \mathrm{E}-\mathrm{PS}$ males displayed a significant decrease in sucrose preference at a low concentration compared with $\mathrm{Ctrl}(n=16)$ male offspring $\left({ }^{*} p<0.05 ; n=16\right)$. B, $\boldsymbol{C}$, Two hours $(\boldsymbol{B})$ and twenty-four hours $(\boldsymbol{C})$ after an acute stress, E-PS males consumed significantly more $10 \%$ sucrose than control $\left({ }^{*} p<0.05\right)$ and undisturbed E-PS ( $\left.{ }^{\#} p<0.05\right)$ males after an overnight sucrose restriction $(n=8) . \boldsymbol{D}, \boldsymbol{E}$, During continuous sucrose access, an acute stress exposure did not influence $2 \mathrm{~h}(\boldsymbol{D})$ or $24 \mathrm{~h}(\boldsymbol{E}) 10 \%$ sucrose intake for control or E-PS males $(n=4)$. Data are mean \pm SEM

To control for the effects of stress during overnight sucrose restriction, we compared intake 2 and $24 \mathrm{~h}$ after acute stress exposure under continuous access conditions. E-PS $\left(F_{2 \mathrm{~h}(1,27)}=\right.$ $\left.1.2, p=0.3 ; F_{24 \mathrm{~h}(1,27)}=0.9, p=0.5\right)$ and acute stress $\left(F_{2 \mathrm{~h}(1,27)}\right.$ $\left.=1.8, p=0.3 ; F_{24 \mathrm{~h}(1,27)}=0.9, p=0.5\right)$ did not influence $2 \mathrm{~h}$ (Fig. $2 D$ ) and 24 h sucrose intake (Fig. 2E).

\section{SSRI treatment}

Because E-PS males exhibit depression-like behaviors in the TST, FST, and sucrose tests, we compared behavioral responses to an acute SSRI. A main effect of E-PS was present $\left(F_{(1,29)}=4.3 ; p<\right.$ $0.05)$, indicating that vehicle-treated E-PS males spent significantly more time immobile than vehicle-treated controls $(p<$ $0.01)$ (Fig. $3 A$ ). There was also a main effect of citalopram treatment on time spent immobile $\left(F_{(2,29)}=3.9 ; p<0.05\right)$ (Fig. $\left.3 A\right)$. Acute administration of $2.5 \mathrm{mg} / \mathrm{kg}$ citalopram $30 \mathrm{~min}$ before testing ameliorated the significant difference in time spent immobile 
Table 1. Average body weights and daily food and water intake each week during sucrose preference testing

\begin{tabular}{|c|c|c|c|c|c|c|c|c|}
\hline & Start & 1 & 2 & 3 & 4 & 5 & Treatment & Day \\
\hline \multicolumn{9}{|c|}{ Body weight (g) } \\
\hline Ctrl & $27.2 \pm 0.5$ & $27.8 \pm 0.5$ & $27.0 \pm 0.5$ & $28.0 \pm 0.3$ & $29.1 \pm 0.5$ & $29.1 \pm 0.51$ & \multirow[t]{2}{*}{$F_{(1,168)}=3.5$} & \multirow[t]{2}{*}{$F_{(5,168)}=13.5^{*}$} \\
\hline E-PS & $25.9 \pm 0.5$ & $26.7 \pm 0.6$ & $26.3 \pm 0.6$ & $26.9 \pm 0.6$ & $27.0 \pm 0.9$ & $27.5 \pm 0.9$ & & \\
\hline \multicolumn{9}{|c|}{ Daily food intake (g) } \\
\hline Ctrl & & $4.0 \pm 0.3$ & $4.0 \pm 0.4$ & $4.0 \pm 0.4$ & $3.4 \pm 0.6$ & $3.4 \pm 0.4$ & \multirow[t]{2}{*}{$F_{(1,168)}=1.3$} & \multirow[t]{2}{*}{$F_{(5,168)}=18.5^{*}$} \\
\hline E-PS & & $4.1 \pm 0.3$ & $3.8 \pm 0.3$ & $3.8 \pm 0.4$ & $3.5 \pm 0.3$ & $3.3 \pm 0.8$ & & \\
\hline \multicolumn{9}{|c|}{ Daily water intake (g) } \\
\hline Ctrl & & $3.1 \pm 0.8$ & $3.8 \pm 0.6$ & $3.4 \pm 0.3$ & $4.5 \pm 0.4$ & $4.5 \pm 0.4$ & \multirow[t]{2}{*}{$F_{(1,168)}=1.1$} & \multirow[t]{2}{*}{$F_{(5,168)}=2.4^{*}$} \\
\hline E-PS & & $4.1 \pm 0.3$ & $4.1 \pm 0.3$ & $4.5 \pm 0.3$ & $3.5 \pm 0.3$ & $3.2 \pm 0.3$ & & \\
\hline
\end{tabular}

between vehicle-treated E-PS and control males $(p=0.7)$ (Fig. $3 A$ ), whereas administration of $10 \mathrm{mg} / \mathrm{kg}$ significantly decreased time spent immobile for control and E-PS mice $(p<0.05)$ (Fig. $3 A)$. A main effect of citalopram $\left(F_{(2,29)}=8.2 ; p<0.05\right)$ (Fig. $3 B$ ) and a significant interaction between citalopram and E-PS $\left(F_{(2,29)}\right.$ $=4.4 ; p<0.05$ ) (Fig. $3 B$ ) influenced number of immobility bouts. Vehicle-treated E-PS males exhibited significantly more bouts of immobility than vehicle-treated controls $(p<0.01)$ (Fig. 3B). Acute SSRI administration at $2.5 \mathrm{mg} / \mathrm{kg}$ significantly decreased bouts of immobility displayed by E-PS males $(p<$ 0.05 ) (Fig. $3 B$ ), but did not affect control males $(p=0.8)$ (Fig. $3 B)$. Administration of $10 \mathrm{mg} / \mathrm{kg}$ significantly decreased bouts of immobility for both control and E-PS males $(p<0.05)$ (Fig. $3 B)$. Latency to first bout of immobility was also measured. There was a main effect of E-PS $\left(F_{(2,29)}=15.5 ; p<0.05\right)($ Fig. $3 C)$ and a significant main effect of citalopram treatment $\left(F_{(2,29)}=4.4 ; p<\right.$ 0.05 ) (Fig. 3C) on latency to first bout of immobility. Supporting our previous findings, vehicle-treated E-PS males displayed a shorter latency to the first bout of immobility $(p<0.01)$ (Fig. $3 C$ ). For E-PS males, both $2.5 \mathrm{mg} / \mathrm{kg}$ citalopram $(p<0.05)$ (Fig. $3 C$ ) and $10 \mathrm{mg} / \mathrm{kg}$ significantly increased latency to first bout of immobility $(p<0.05)$ (Fig. $3 B$ ). For control males, there was no effect of $2.5 \mathrm{mg} / \mathrm{kg}$ citalopram $(p=0.3)$ (Fig. $3 C$ ) or $10 \mathrm{mg} / \mathrm{kg}$ citalopram $(p=0.2)$ (Fig. $3 C)$ on latency to first bout of immobility.

\section{Serotonin transporter autoradiography}

To examine possible effects of E-PS on SERT levels that may be contributing to the increased SSRI sensitivity in males, SERT levels were measured by autoradiography. E-PS males showed a significant reduction in SERT levels in the CA1 $\left(F_{(1,7)}=25.6 ; p<\right.$ $0.05)$ and CA2 $\left(F_{(1,7)}=7.6 ; p=0.04\right)$ (Fig. $\left.4 A, B\right)$ region of the hippocampus compared with control males. No differences were present in the hypothalamus $\left(F_{(1,7)}=0.8 ; p=0.4\right)$, lateral septum $\left(F_{(1,7)}=2.7 ; p=0.16\right)$, or CA3 regions of the hippocampus $\left(F_{(1,7)}\right.$ $=2.0 ; p=0.2$ ).

Dorsal raphe TPH2, SERT, and 5-HT ${ }_{1 A}$ expression analysis Because the dorsal raphe provides serotonergic input to the hippocampus, expression levels of TPH2, serotonin 1a receptor (5$\mathrm{HT}_{1 \mathrm{~A}}$ ), and SERT were measured on dorsal raphe punches by quantitative real-time PCR. Gene expression analysis showed an apparent increase in TPH2 expression $\left(F_{(1,7)}=5.7 ; p=0.06\right)$ (Fig. $4 B$ ). No differences in SERT $\left(F_{(1,7)}=0.9 ; p=0.4\right)$ (Fig. $4 C$ ) or $5-\mathrm{HT}_{1 \mathrm{~A}}\left(F_{(1,7)}=0.3 ; p=0.7\right.$ ) (Fig. $4 D$ ) expression were present.

\section{$C R F$ in situ hybridization}

Because stress responsivity can be regulated by CRF, we examined CRF expression by in situ hybridization. In the central nucleus of the amygdala, E-PS males showed a significant elevation in expression compared with controls $(p<0.01)$ (Fig. $5 A, B)$.
HPA axis stress response

Because increased stress sensitivity is a core component of affective disorders, corticosterone levels were compared between E-PS and control adult male offspring after a 15 min stress exposure. Early prenatal stress treatment $\left(F_{(1,18)}=9.2 ; p<0.05\right)$ and 15 min stress exposure $\left(F_{(3,20)}=14.2 ; p<0.05\right)$ significantly altered corticosterone levels. E-PS did not influence baseline corticosterone levels. E-PS males have significantly elevated corticosterone levels after $15 \mathrm{~min}$ of restraint (time 15; $p<0.05$ ), and $15 \mathrm{~min}$ after stress end (time $30 \mathrm{~min} ; p<0.05$ ) (Fig. $5 C$ ). The recovery of E-PS males appeared to be delayed, with corticosterone levels 45 min after stress end remaining elevated $(p=0.07)$ (Fig. $5 C$ ).

\section{GR in situ hybridization}

E-PS significantly decreased GR expression in the CA3 $(p<$ $0.05)$ and DG regions of the hippocampus $(p<0.05)$ (Fig. $5 D, E)$. A nonsignificant reduction was also seen in CA1 after early prenatal stress $(p=0.06)$ (Fig. $5 D, E)$. No differences were detected in the CA2 region $(p=0.4)$ (Fig. $5 D, E)$.

\section{Analysis of DNA methylation of CRF, GR, and BDNF genes}

Because previous studies have shown that early life experience can alter the epigenome, we investigated whether changes in methylation were driving altered expression of CRF and GR (Weaver, 2004a). In the hypothalamus, cytosine-methylation analysis within the CRF promoter revealed main effects of base pair position $\left(F_{(8,51)}\right.$ $=44.25 ; p<0.05)$ and early prenatal stress exposure $\left(F_{(1,51)}=4.35\right.$; $p<0.05)$ with reduced methylation in E-PS males $(p<0.05)$ (Fig. $6 A$ ). No differences in methylation between prenatal stress treatments were evident within analyzed region of the CRF intron $\left(F_{(1,51)}\right.$ $=1.35 ; p=0.4)($ Fig. $6 B)$. Analysis of methylation levels within the exon $1_{7}$ region of the GR promoter revealed significant main effects of base pair position $\left(F_{(8,51)}=10.5 ; p<0.05\right)$ and E-PS $\left(F_{(1,51)}=\right.$ $4.35 ; p<0.05)$ with increased methylation in E-PS males $(p<0.05)$ (Fig. $6 C$ ). No effect of E-PS was evident in the promoter region of $\operatorname{BDNF}\left(F_{(1,51)}=0.75 ; p>0.7\right)$ (Fig. $\left.6 D\right)$. Similar to effects in hypothalamic tissue, in DNA isolated from the central nucleus of the amygdala, cytosine-methylation analysis within the CRF promoter revealed main effects of base pair position $\left(F_{(8,50)}=34.5 ; p<0.05\right)$ and early prenatal stress exposure $\left(F_{(1,50)}=3.65 ; p<0.05\right)$ with reduced methylation in E-PS males $(-336$ bp: $\mathrm{Ctrl}=67.2 \pm 2.8$, $\mathrm{E}-\mathrm{PS}=62.1 \pm 2.5 ;-232$ bp: $\mathrm{Ctrl}=58.2 \pm 3.3, \mathrm{E}-\mathrm{PS}=62.9 \pm 4.8$; -226 bp: $\mathrm{Ctrl}=52.5 \pm 2.4, \mathrm{E}-\mathrm{PS}=52.4 \pm 3.8 ;-212 \mathrm{bp}: \mathrm{Ctrl}=$ $73.6 \pm 3.1, \mathrm{E}-\mathrm{PS}=64.9 \pm 5.4 ;-147 \mathrm{bp}: \mathrm{Ctrl}=45.1 \pm 7.0, \mathrm{E}-\mathrm{PS}=$ $36.2 \pm 5.49 ;-101$ bp: Ctrl $=42.2 \pm 8.0$, E-PS $=37.8 \pm 4.98 ;-95$ bp: Ctrl = 35.8 \pm 9.6, E-PS $=19.7 \pm 3.25 ;-79$ bp: Ctrl $=42.8 \pm$ 9.0, $\mathrm{E}-\mathrm{PS}=37.5 \pm 5.3 ;-55 \mathrm{bp}: \mathrm{Ctrl}=28.8 \pm 3.6, \mathrm{E}-\mathrm{PS}=24.5 \pm$ 1.3 ; -36 bp: $\mathrm{Ctrl}=24.9 \pm 2.6, \mathrm{E}-\mathrm{PS}=18.8 \pm 2.6$ ). 
A

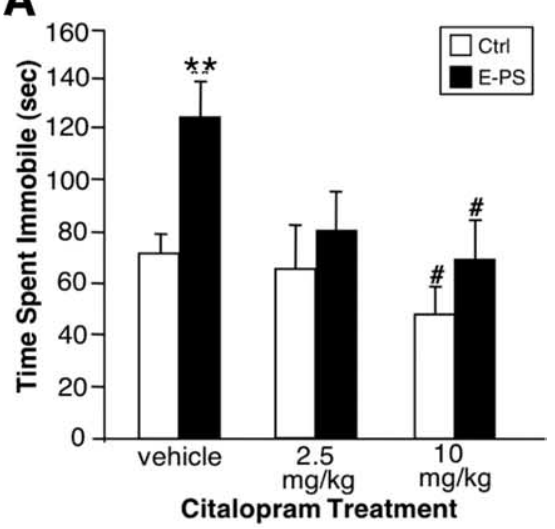

B
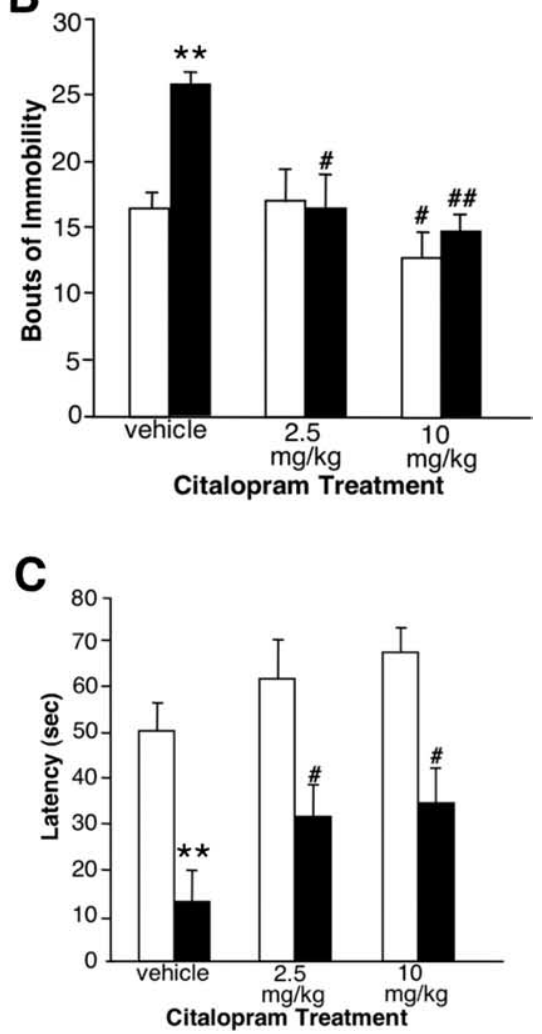

Figure 3. E-PS males showed an increased sensitivity to acute SSRI treatment. $\boldsymbol{A}-\boldsymbol{C}$, In a tail suspension test, E-PS males spent more time immobile $(\boldsymbol{A})$, displayed an increased number of immobility bouts $(\boldsymbol{B})$, and showed a decreased latency to first bout of immobility $(\boldsymbol{C})$ compared with control males $\left({ }^{* *} p<0.01\right)$. For E-PS males, a subthreshold dose of $2.5 \mathrm{mg} / \mathrm{kg}$ citalopram significantly reduced bouts of immobility $(\boldsymbol{B})$ and latency to first bout of immobility $\left(\boldsymbol{C} ;{ }^{\#} p<\right.$ 0.05 ) compared with vehicle. Citalopram ( $10 \mathrm{mg} / \mathrm{kg}$ ) significantly reduced time spent immobile and bouts of immobility for control and E-PS males ( ${ }^{\#} p<0.05$; $\left.{ }^{\# \#} p<0.01\right)$ compared with vehicle. C, Citalopram (10 mg/kg) also significantly increased latency to first bout of immobility for E-PS males ( $\left.{ }^{\#} p<0.05\right)$. Data are mean \pm SEM. $n=8$.

PCR array analysis of placental gene expression

To determine the underlying mechanism driving the sex-specific effects of early prenatal stress, control and E-PS day 12 placentas of male and female embryos were examined using a focused PCR array. E-PS, offspring sex, and an interaction between offspring sex and E-PS significantly influenced placental expression of peroxisome proliferator-activated receptor $\alpha(\operatorname{PPAR} \alpha)$, insulin-like growth factor binding protein 1 (IGFBP-1), glucose transporter 4 (GLUT4), and hypoxia-inducible factor 3a (HIF3a) (Table 2).
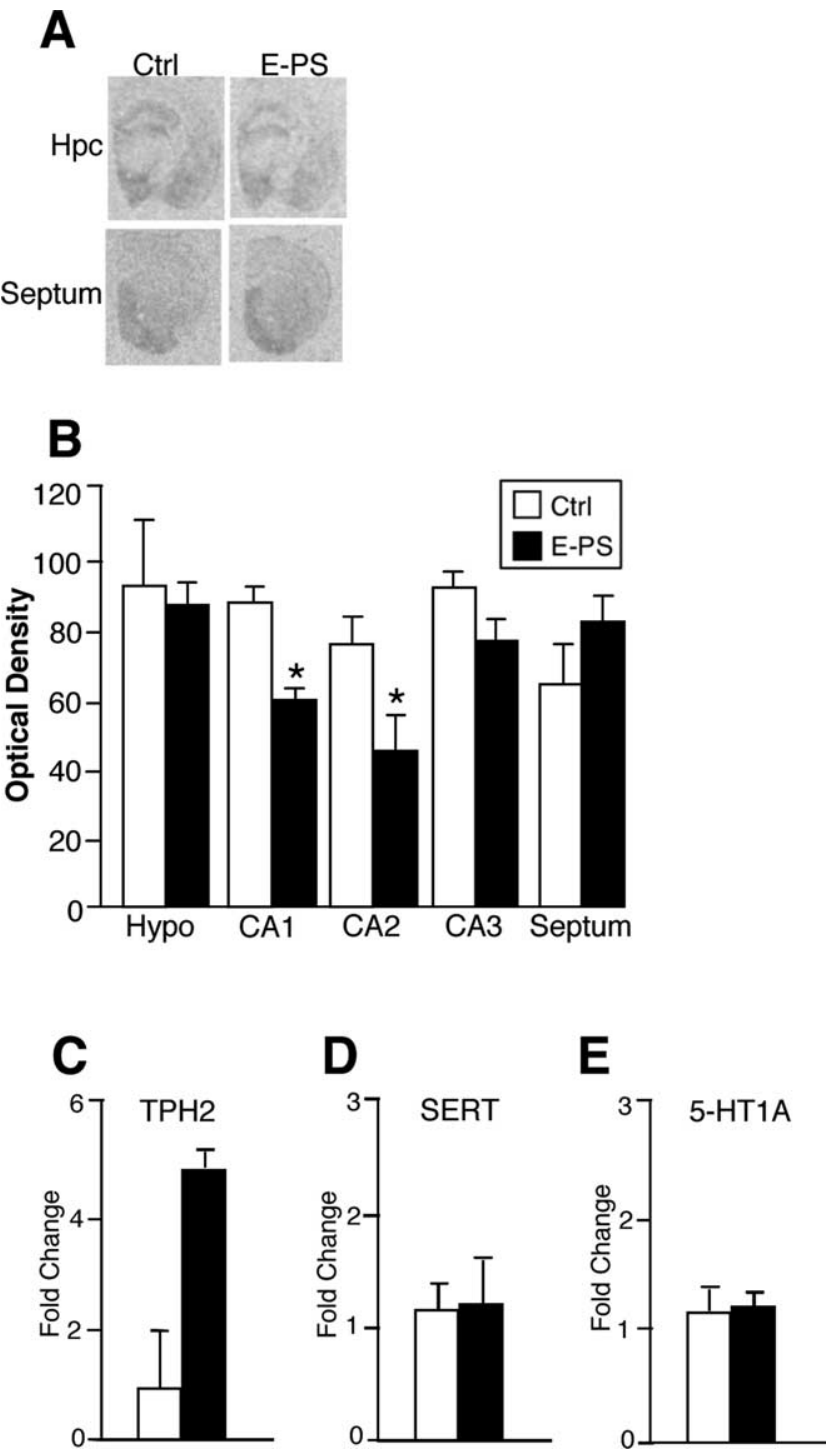

Figure 4. E-PS males showed altered serotonin transporter levels. $A, B, E-P S$ males showed a significant reduction in SERT levels in the CA1 region of the hippocampus compared with control males ( $\left.{ }^{*} p<0.05\right)$. C, Real-time PCR performed on dorsal raphe micropunches revealed no significant effect of E-PS on TPH2 expression $(p=0.06) . \boldsymbol{D}, \boldsymbol{E}$, No differences were detected in SERT $(\boldsymbol{D})$ or $5-\mathrm{HT}_{1 \mathrm{~A}}(\boldsymbol{E})$ expression in the dorsal raphe. Data are mean \pm SEM. $n=4-5$. Hpc, Hippocampus; Hypo, hypothalamus.

Compared with control male placentas, E-PS male placentas showed significant upregulation of PPAR $\alpha$ (4.7-fold; $p<0.01$ ) (Fig. 7A), IGFBP-1 (8.1-fold; $p<0.01$ ) (Fig. 7A), GLUT4 (3.6fold; $p<0.01$ ) (Fig. 7), and HIF3a (2.9-fold; $p<0.01$ ) (Fig. 7A). In contrast, E-PS female placentas showed significant downregulation of $\operatorname{PPAR} \alpha$ (3.2-fold; $p<0.01$ ), and a trending downregulation of IGFBP-1 (4.7-fold; $p=0.06$ ) compared with female control placentas. For a complete list of genes and fold changes, see supplemental Tables 1 and 2 (available at www.jneurosci.org as supplemental material).

Placental TNF $\alpha$ and IL-6 expression analysis

TNF $\alpha$ expression was not altered by offspring sex $(p=0.8)$ or E-PS $(p=0.13$ ) (Fig. 7B). IL-6 expression was not altered by sex $(p=0.4)$ or E-PS $(p=0.07)$ (Fig. $7 C)$.

Placental DNMT1, DNMT3a, and MeCP2 expression analysis DNMT1 expression was altered by offspring sex $\left(F_{(1,11)}=5.4\right.$; $p<0.05)$ and E-PS $\left(F_{(1,11)}=4.8 ; p<0.05\right)$. Control male pla- 

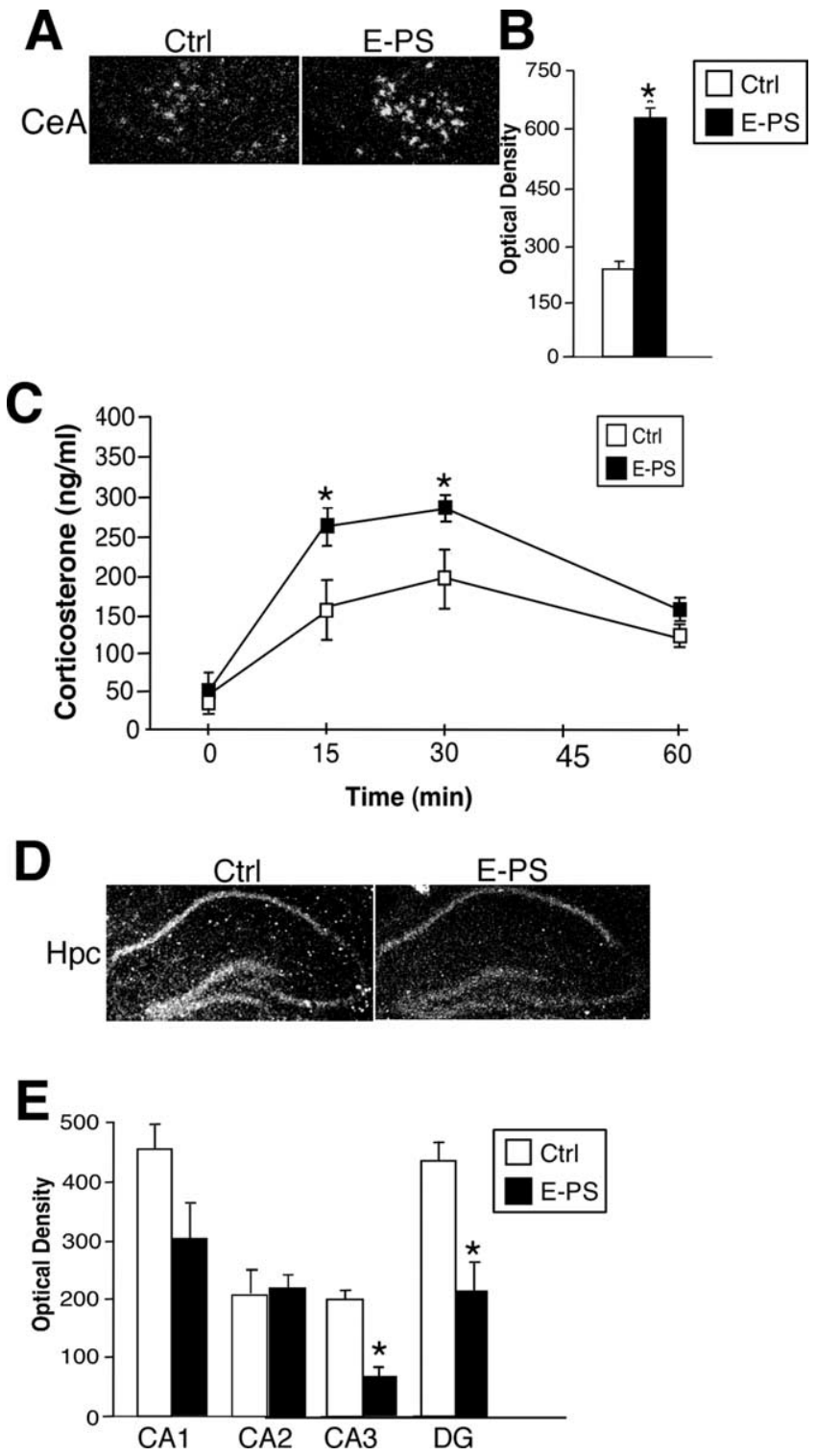

Figure 5. E-PS males displayed stress pathway dysregulation including increased CeA CRF, decreased hippocampal GR, and an increased HPA axis stress response. A, B, E-PS significantly increased CRF expression in the central nucleus of the amygdala compared with controls $\left({ }^{*} p<\right.$ $0.05 ; n=4)$. C, Corticosterone levels after a 15 min restraint stress were significantly higher in E-PS males compared with controls $\left({ }^{*} p<0.05 ; n=6\right) . \boldsymbol{D}, \boldsymbol{E}$, GR expression was significantly lower in E-PS males compared with controls in the CA3 and DG of the dorsal hippocampus ( ${ }^{*} p<$ 0.05 ). The apparent decrease in CA1 GR expression was not significant $(p=0.07 ; n=5)$. № effect of E-PS was seen in CA2. Data are mean \pm SEM. Hpc, Hippocampus.

centas had significantly lower expression of DNMT1 than control female placentas $(p<0.01)$ (Fig. $7 D)$. Furthermore, E-PS significantly increased DNMT1 expression in female placentas $(p<$ 01) (Fig. $7 D)$, but not male placentas $(p=0.15)$ (Fig. $7 D$ ). DNMT3a expression was not altered by sex $(p=0.1)$ or E-PS $(p=0.1)$ (Fig. $7 E)$. MeCP2 expression was not altered by sex $(p=0.9)$ or E-PS $(p=0.2)$ (Fig. $7 F)$.

Western blot analysis

As a gross assessment of possible sex-specific delays in brain development after prenatal stress early in gestation, levels of NF-1 were compared in postnatal day 1 brains of E-PS male and female pups. Additionally, vascular endothelial growth factor (VEGF) was examined to determine the influence of prenatal stress on the

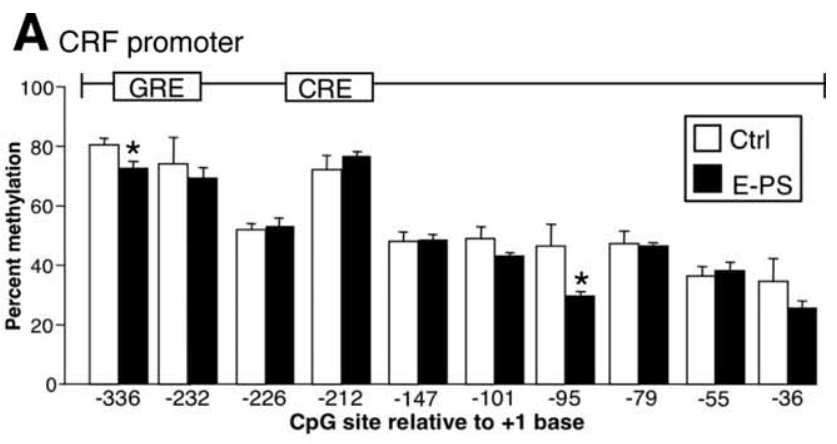

\section{B CRF intron}
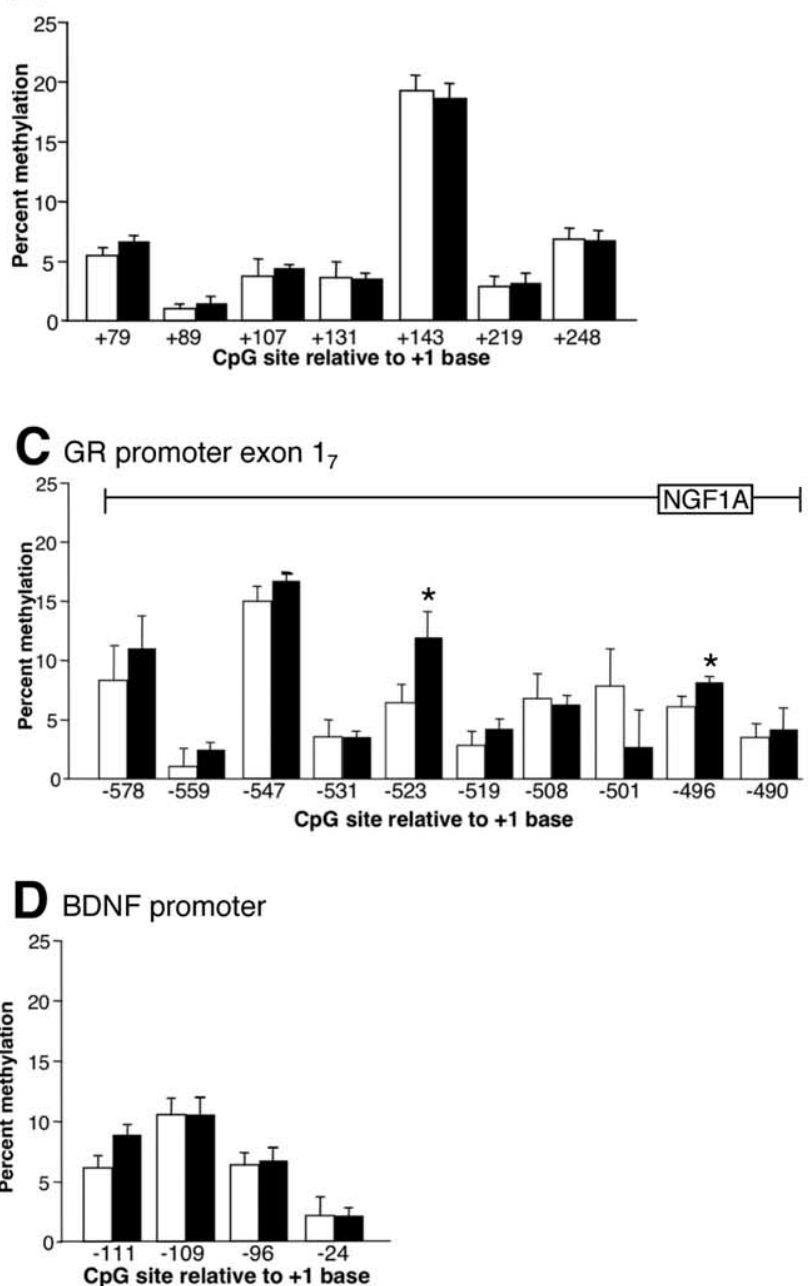

Figure 6. Alterations in DNA methylation of CRF and GR in E-PS males correlated with directional changes in gene expression patterns. $A$, Methylation analysis of the $10 \mathrm{CpG}$ dinucleotides within the CRF promoter ( -336 to $-36 \mathrm{bp}$ ) revealed a significant decrease in methylation at specific cytosines in E-PS males compared with control males $\left({ }^{*} p<0.05\right)$. $\boldsymbol{B}$, No change in methylation was evident in the CRF intronic region (79-248 kb). C, A significant decrease in methylation at specific cytosines in E-PS males compared with control males was detected in the GR promoter region $(-578$ to $-490 \mathrm{bp})\left({ }^{*} p<0.05\right)$. D, No changes in methylation were detected in the promoter region ( -111 to -24 bp) of BDNF. Data are mean \pm SEM. $n=4$.

developing vasculature. E-PS males showed a significant decrease in whole-brain NF-1 $(p<0.05)$ (Fig. $8 A)$. No effect of early prenatal stress was seen in female NF-1 levels $(p=0.7$ ) (Fig. $8 B$ ). No differences were found between groups at 4 months of age in NF-1 in prefrontal cortex $(p=0.8)$ (Fig. $8 C)$. Early prenatal stress did not significantly influence postnatal day 1 male $(p=$ 0.7 ) (Fig. $8 D$ ) or female ( $p=0.9$ ) (Fig. $8 E$ ) VEGF levels. 
Table 2. Effect of E-PS and offspring sex on placental gene expression on gestational day 12

\begin{tabular}{llll}
\hline Gene & E-PS & Sex & Sex $\times$ E-PS \\
\hline IGFBP-1 & $F_{(1,10)}=0.8$ & $F_{(1,10)}=37.9^{*}$ & $F_{(1,10)}=7.0^{*}$ \\
PPAR $\alpha$ & $F_{(1,10)}=0.1$ & $F_{(1,10)}=41.2^{* *}$ & $F_{(1,10)}=5.6^{*}$ \\
GLUT4 & $F_{(1,10)}=49.6^{*}$ & $F_{(1,10)}=205.1^{* *}$ & $F_{(1,10)}=51.2^{*}$ \\
HIF3 $\alpha$ & $F_{(1,10)}=63.6^{*}$ & $F_{(1,10)}=3.8$ & $F_{(1,10)}=5.7^{*}$ \\
\hline
\end{tabular}

${ }^{*} p<0.05 ;{ }^{* *} p<0.001$.
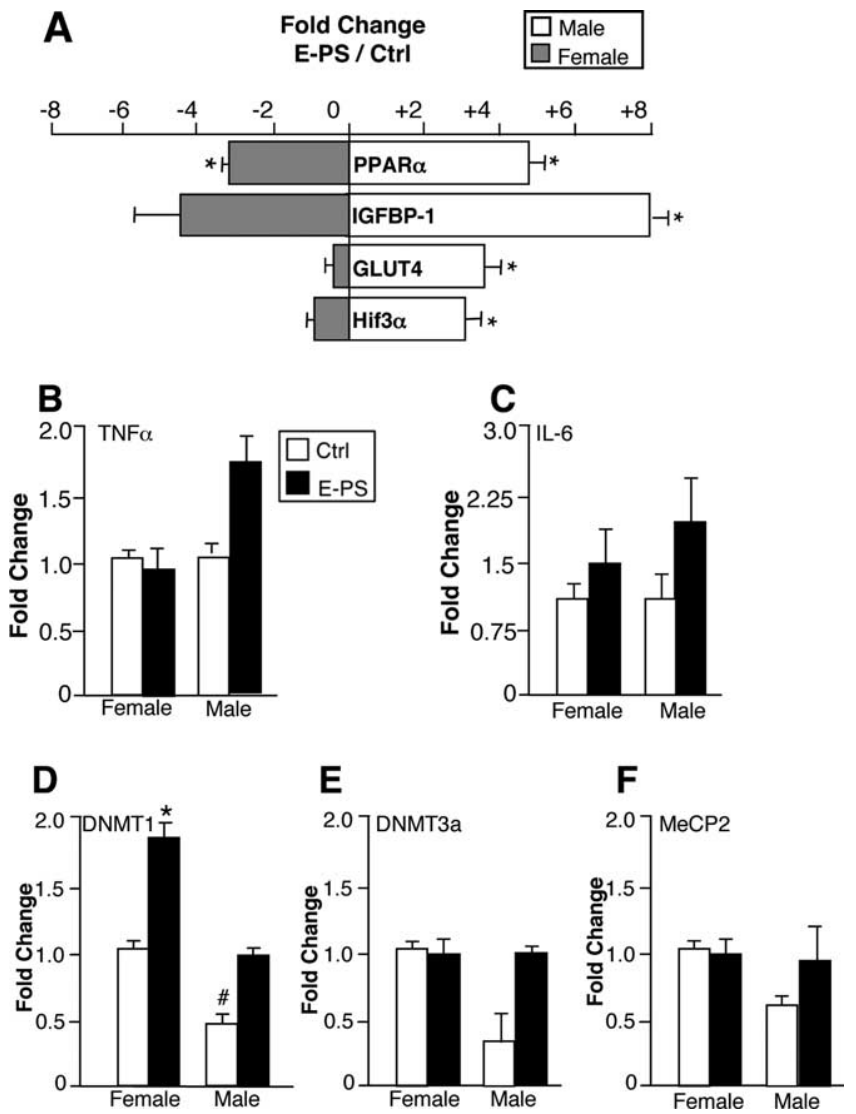

Figure 7. E-PS male placentas showed robust changes in expression of genes critical for growth and development signals. A, E-PS male placentas showed significant upregulation of PPAR $\alpha$, IGFBP-1, GLUT4, and HIF3 $\alpha$ compared with male control placentas $\left({ }^{*} p<0.01\right)$. In contrast, E-PS female placentas showed significant downregulation of PPAR $\alpha\left({ }^{*} p<0.01\right)$ and a trending downregulation of IGFBP-1 ( $p=0.06)$ compared with female control placentas. $\boldsymbol{B}$, $\boldsymbol{C}$, TNF $\alpha(\boldsymbol{B})$ and IL-6 ( $\boldsymbol{C}$ ) expression levels were not significantly altered by sex or E-PS $(n=5)$. $\boldsymbol{D}$, In our analysis of sex differences in placental epigenetic machinery, control male placentas showed significantly lower expression of DNMT1 compared with control female placentas $\left({ }^{\#} p<0.01\right)$. E-PS increased expression of DNMT1 in female placentas $\left({ }^{*} p<0.05\right)$. No effect of E-PS was detected in male DNMT1 levels. $\boldsymbol{E}, \boldsymbol{F}$, DNMT3a $(\boldsymbol{E})$ and MeCP2 $(\boldsymbol{F})$ expression levels were not significantly altered by sex or E-PS $(n=4)$. Data are mean \pm SEM.

\section{Discussion}

The mortality and morbidity resulting from neurodevelopmental and mood disorders has remained largely unchanged over the last 50 years (Insel and Scolnick, 2006). Given the difficulty in treating these diseases, a cross-disciplinary approach that identifies the developmental origin of disease and vulnerable populations is needed to create novel prevention and treatment strategies. The predisposition toward sex-biased disorders, including schizophrenia, autism, and affective disorders, has been associated with stress-related fetal antecedents (Ward, 1991; Watson et al., 1999; Pardo and Eberhart, 2007). However, the mechanism underlying this influence of PS remains unclear. In our studies, behavioral
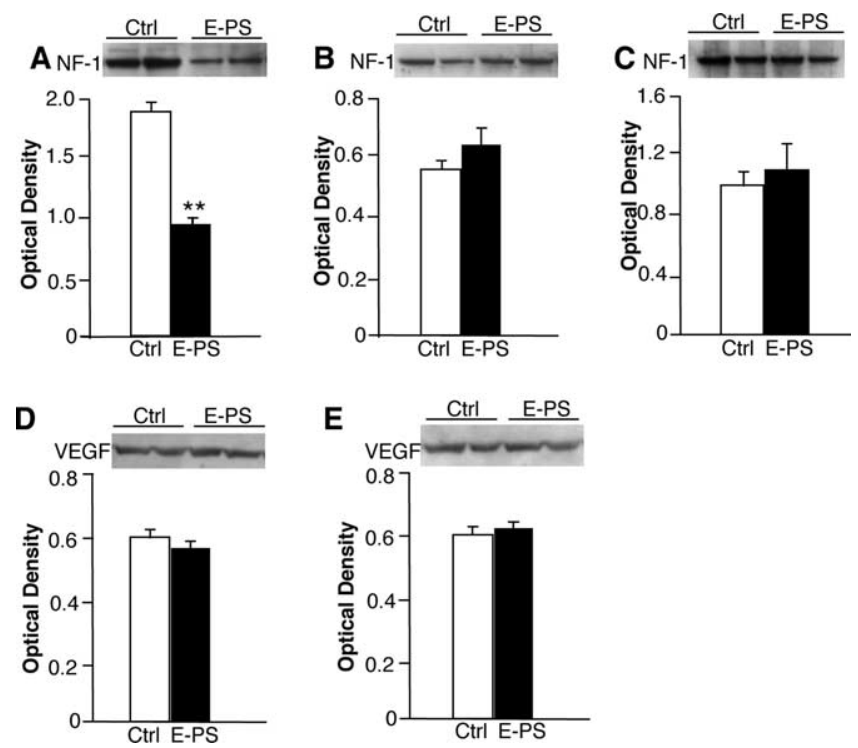

Figure 8. Significant decreases in brain NF-1 levels in E-PS males support delayed CNS development. As a gross marker of brain development, we compared NF-1 levels from postnatal day 1 male and female offspring. $\boldsymbol{A}$, Whole-brain levels of NF-1 were significantly decreased in E-PS males compared with control male levels at postnatal day $1\left({ }^{* *} p<0.01\right)$. B , NF-1 levels were not different between E-PS and Ctrl females at postnatal day 1.C, Prefrontal cortex levels of NF-1 were not different between E-PS and control male adults ( 16 weeks). $\boldsymbol{D}, \boldsymbol{E}$, There was no significant effect of E-PS on VEGF in male $(\boldsymbol{D})$ or female $(\boldsymbol{E})$ postnatal day 1 brains. Data are mean \pm SEM. $n=3-4$.

coping responses of male and female offspring exposed to stress across gestation were initially examined to determine whether temporal specificity may underlie a sex-dependent vulnerability to prenatal stress.

Male offspring exposed to E-PS exhibited maladaptive behaviors in both the tail suspension and forced swim tests. Although female controls generally showed increased immobility compared with males, prenatal stress did not further alter stress coping responses. Because of the existing sex differences in these tests, a ceiling effect may have precluded prenatal stress from further altering female outcomes. Interestingly, our data correlate with the recent clinical findings that show stress early in pregnancy increased the presence of schizophrenia in males, supporting a sex-specific risk early in development (Khashan et al., 2008). Although our previous studies have reported effects of stress during additional gestational time points on parameters of learning and memory and energy balance regulation (Mueller and Bale, 2006, 2007), our current results reveal a vulnerability of stress pathway programming specific to early pregnancy.

Because the male E-PS increased immobility in the tail suspension and forced swim tests was suggestive of a depression-like phenotype, we also examined hedonic sensitivity in these mice using a sucrose preference test (Moreau, 1997). E-PS males exhibited a diminished preference for a $1 \%$ sucrose solution, suggesting a diminished basal sensitivity to hedonic rewards. However, an acute stress exposure induced E-PS males to consume $100 \%$ more sucrose in the $2 \mathrm{~h}$ after a sucrose deprivation compared with continuous access mice. The majority of the difference between control and E-PS $24 \mathrm{~h}$ sucrose consumption resulted from this $2 \mathrm{~h}$ intake, indicative of stress-induced bingeing responses (Lynch and Taylor, 2005; Avena et al., 2006).

Given the depression-like phenotype of E-PS males, behavioral responses to an acute SSRI, citalopram, were measured. E-PS males exhibited a greater sensitivity to a subthreshold dose of citalopram in 
a tail suspension test. Because this test measures active coping behaviors that are responsive to acute changes in synaptic 5-HT, the greater sensitivity detected in E-PS males may indicate a dysregulation in 5-HT pathways. Further examination of the 5-HT system in these mice revealed reduced 5-HT transporter levels in the hippocampus and a trend for increased tryptophan hydroxylase- 2 expression in the dorsal raphe. Thus, potential increased 5-HT output and decreased reuptake may underlie the increased sensitivity to acute SSRI treatment in these mice.

Dysregulation of the serotonin system has been classically linked to the etiology of affective disorders. CRF is a known regulator of 5-HT neurotransmission and a key determinant of stress responsivity (Valentino et al., 1991; Bale and Vale, 2004; Tan et al., 2004). Therefore, dysregulation of CRF and stress pathway components could be an upstream contributor to abnormalities in 5-HT transmission and a stress-sensitive phenotype. In the CeA, E-PS males showed a significant increase in CRF expression. As an additional indication of increased stress responsiveness, E-PS males also exhibited higher corticosterone levels after an acute restraint stress, and decreased hippocampal GRs. Although previous studies have reported similar changes in GR levels after stress experienced late in gestation, our results indicate an earlier developmental window during which stress pathways display a sex-specific vulnerability (Cratty et al., 1995; Darnaudéry and Maccari, 2008).

The long-term impact of prenatal stress on regulation of central gene expression may occur via effects on the epigenome. In our examination of the methylation pattern of CRF, we report reductions in methylation at specific cytosines within the identified CRF promoter CpG island in both the hypothalamus and CeA that may contribute to the increased CRF detected in these mice. In our examination of the exon $1_{7}$ region of the GR promoter, E-PS males showed a site-specific increase in methylation that occurred in the region containing the consensus sequence of NGFI-A (nerve growth factor inducible-A), where methylation status has previously been linked to early life experience and decreased expression (Weaver et al., 2004a,b).

Because the fetal brain is not present during this period of early stress, we hypothesized that sex-specific changes in fetal development and long-term sensitivity may occur through actions on the placenta as it is derived from the developing blastocyst and undergoes critical development during this period of E-PS (Hemberger, 2007). The placenta is the intermediary by which the maternal hormonal milieu influences the developing embryo, and therefore is poised to be influenced by perturbations occurring early in pregnancy that could affect fetal development throughout pregnancy by altering (1) nutrient and oxygen transport, (2) inflammatory responses, and (3) epigenetic programming machinery. To examine this hypothesis, we examined effects of E-PS on male and female placental gene expression patterns using a focused PCR array for growth factors and nutrient transport genes. E-PS male placentas exhibited significant increases in PPAR $\alpha$, IGFBP-1, GLUT4, and HIF3 $\alpha$. Surprisingly, E-PS female placentas showed a reduction in $\operatorname{PPAR} \alpha$ and IGFBP-1 expression. Because glucocorticoids increase expression of PPAR $\alpha$ (Lemberger et al., 1994), and PPAR $\alpha$ in turn increases expression of IGFBP-1 (Degenhardt et al., 2006), our results support a potential mechanism whereby maternal stress could directly affect placental gene expression patterns. Reductions in growth factors have been linked to affective and neurodevelopmental disorders (Malberg et al., 2007). Thus, an elevation in placental IGFBP-1 and a consequent decrease in available growth factors during critical developmental periods may play a role in male fetal programming.
Alterations in oxygen and nutrient availability have been associated with inflammation (Altay et al., 2004), and because recent studies have shown an important link between inflammatory events and the onset of major depression (Dantzer et al., 2008), additional comparisons of placental inflammatory markers were conducted. Although no significant differences were detected for levels of TNF $\alpha$ and IL- 6 at this time point, it is interesting that male placentas showed a directional change suggestive of possible inflammation after the E-PS that may be more robust at different pregnancy time points.

To further investigate potential mechanisms underlying the sex-specific effect of E-PS on placenta gene expression, we examined DNA methylation machinery in male and female placentas. Interestingly, expression of DNMT1, the enzyme responsible for methylation maintenance, was significantly lower in male control placentas compared with female control placentas, providing support for our hypothesis that the influence of E-PS may begin at the level of the placenta (Leonhardt et al., 1992). In addition, although E-PS appeared to increase DNMT1 expression in both sexes, this change was only significant in females. Because previous studies have shown that the maintenance of methylation patterns is critical in neurodevelopment, and perturbations in placental DNA methylation patterns are strong predictors of fetal changes, a stress-induced elevation of DNMT1 may indicate that females are able to circumvent the effects of stress by strengthening the maintenance of methylation during this perturbation (Rivera et al., 2008; Wang et al., 2008).

These changes in placental gene expression related to growth factors, nutrient transport, and epigenetics may impact the developing CNS. As a gross marker of brain development, we compared NF-1 levels from postnatal day 1 male and female offspring. E-PS males but not females showed a significant reduction in NF-1, supporting a possible delay in brain development. Because neuronal abnormalities and delayed development have been associated with major depressive disorder and schizophrenia, such changes in central NF-1 may be predictive of future disease (Reinés et al., 2004; Miguel-Hidalgo et al., 2005). No effects of E-PS were detected in NF-1 levels in adult males, indicating that E-PS males eventually catch up with control males.

In summary, because it is unlikely that any one specific gene produces the difference in behaviors detected between control and E-PS males, an array of genetic, hormonal, and epigenetic factors were examined in these studies. Our results support the hypothesis that E-PS dysregulation of CRF and stress pathway programming may be a key contributor to the stress-sensitive phenotype detected in these male mice, including the increased immobility in the tail suspension and forced swim tests, heightened HPA axis responsivity, and influences on the 5-HT system. These studies provide critical mechanistic insight regarding the underlying programming of sexbiased neurodevelopmental disorders.

\section{References}

Altay T, Gonzales ER, Park TS, Gidday JM (2004) Cerebrovascular inflammation after brief episodic hypoxia: modulation by neuronal and endothelial nitric oxide synthase. J Appl Physiol 96:1223-1230; discussion 1196.

Avena NM, Rada P, Moise N, Hoebel BG (2006) Sucrose sham feeding on a binge schedule releases accumbens dopamine repeatedly and eliminates the acetylcholine satiety response. Neuroscience 139:813-820.

Bale TL, Vale WW (2004) CRF and CRF receptors: role in stress responsivity and other behaviors. Annu Rev Pharmacol Toxicol 44:525-557.

Bale TL, Contarino A, Smith GW, Chan R, Gold LH, Sawchenko PE, Koob GF, Vale WW, Lee KF (2000) Mice deficient for corticotropin-releasing hormone receptor-2 display anxiety-like behaviour and are hypersensitive to stress. Nat Genet 24:410-414. 
Bale TL, Anderson KR, Roberts AJ, Lee KF, Nagy TR, Vale WW (2003) Corticotropin-releasing factor receptor-2-deficient mice display abnormal homeostatic responses to challenges of increased dietary fat and cold. Endocrinology 144:2580-2587.

Cratty MS, Ward HE, Johnson EA, Azzaro AJ, Birkle DL (1995) Prenatal stress increases corticotropin-releasing factor (CRF) content and release in rat amygdala minces. Brain Res 675:297-302.

Crowley JJ, Blendy JA, Lucki I (2005) Strain-dependent antidepressant-like effects of citalopram in the mouse tail suspension test. Psychopharmacology 183:257-264.

Cryan JF, Lucki I (2000) 5-HT4 receptors do not mediate the antidepressant-like behavioral effects of fluoxetine in a modified forced swim test. Eur J Pharmacol 409:295-299.

Cryan JF, Page ME, Lucki I (2005) Differential behavioral effects of the antidepressants reboxetine, fluoxetine, and moclobemide in a modified forced swim test following chronic treatment. Psychopharmacology 182:335-344.

Dantzer R, O'Connor JC, Freund GG, Johnson RW, Kelley KW (2008) From inflammation to sickness and depression: when the immune system subjugates the brain. Nat Rev Neurosci 9:46-56.

Darnaudéry M, Maccari S (2008) Epigenetic programming of the stress response in male and female rats by prenatal restraint stress. Brain Res Rev 57:571-585.

Degenhardt T, Matilainen M, Herzig KH, Dunlop TW, Carlberg C (2006) The insulin-like growth factor-binding protein 1 gene is a primary target of peroxisome proliferator-activated receptors. J Biol Chem 281:39607-39619.

Gillott A, Standen PJ (2007) Levels of anxiety and sources of stress in adults with autism. J Intellect Disabil 11:359-370.

Hagan MM, Chandler PC, Wauford PK, Rybak RJ, Oswald KD (2003) The role of palatable food and hunger as trigger factors in an animal model of stress induced binge eating. Int J Eat Disord 34:183-197.

Hemberger M (2007) Epigenetic landscape required for placental development. Cell Mol Life Sci 64:2422-2436.

Insel TR, Scolnick EM (2006) Cure therapeutics and strategic prevention: raising the bar for mental health research. Mol Psychiatry 11:11-17.

Khashan AS, Abel KM, McNamee R, Pedersen MG, Webb RT, Baker PN, Kenny LC, Mortensen PB (2008) Higher risk of offspring schizophrenia following antenatal maternal exposure to severe adverse life events. Arch Gen Psychiatry 65:146-152.

Kim HR, Hwang KA, Kim KC, Kang I (2007) Down-regulation of IL7Ralpha expression in human T cells via DNA methylation. J Immunol 178:5473-5479.

Koenig JI, Kirkpatrick B, Lee P (2002) Glucocorticoid hormones and early brain development in schizophrenia. Neuropsychopharmacology 27:309-318.

Lemberger T, Staels B, Saladin R, Desvergne B, Auwerx J, Wahli W (1994) Regulation of the peroxisome proliferator-activated receptor alpha gene by glucocorticoids. J Biol Chem 269:24527-24530.

Leonhardt H, Page AW, Weier HU, Bestor TH (1992) A targeting sequence directs DNA methyltransferase to sites of DNA replication in mammalian nuclei. Cell 71:865-873.

Liu T, Zhang X, So CK, Wang S, Wang P, Yan L, Myers R, Chen Z, Patterson AP, Yang CS, Chen X (2007) Regulation of Cdx2 expression by promoter methylation, and effects of Cdx2 transfection on morphology and gene expression of human esophageal epithelial cells. Carcinogenesis 28:488-496.

Lucki I (1997) The forced swimming test as a model for core and component behavioral effects of antidepressant drugs. Behav Pharmacol 8:523-532.

Lynch WJ, Taylor JR (2005) Decreased motivation following cocaine selfadministration under extended access conditions: effects of sex and ovarian hormones. Neuropsychopharmacology 30:927-935.

Malberg JE, Platt B, Rizzo SJ, Ring RH, Lucki I, Schechter LE, RosenzweigLipson S (2007) Increasing the levels of insulin-like growth factor-I by an IGF binding protein inhibitor produces anxiolytic and antidepressantlike effects. Neuropsychopharmacology 32:2360-2368.

McGill BE, Bundle SF, Yaylaoglu MB, Carson JP, Thaller C, Zoghbi HY (2006) Enhanced anxiety and stress-induced corticosterone release are associated with increased Crh expression in a mouse model of Rett syndrome. Proc Natl Acad Sci U S A 103:18267-18272.

Meaney MJ, Szyf M, Seckl JR (2007) Epigenetic mechanisms of perinatal programming of hypothalamic-pituitary-adrenal function and health. Trends Mol Med 13:269-277.

Miguel-Hidalgo JJ, Dubey P, Shao Q, Stockmeier C, Rajkowska G (2005) Unchanged packing density but altered size of neurofilament immunoreactive neurons in the prefrontal cortex in schizophrenia and major depression. Schizophr Res 76:159-171.

Moreau JL (1997) Validation of an animal model of anhedonia, a major symptom of depression (in French). Encephale 23:280-289.

Mueller BR, Bale TL (2006) Impact of prenatal stress on long term body weight is dependent on timing and maternal sensitivity. Physiol Behav 88:605-614.

Mueller BR, Bale TL (2007) Early prenatal stress impact on coping strategies and learning performance is sex dependent. Physiol Behav 91:55-65.

Nestler EJ, Barrot M, DiLeone RJ, Eisch AJ, Gold SJ, Monteggia LM (2002) Neurobiology of depression. Neuron 34:13-25.

Pardo CA, Eberhart CG (2007) The neurobiology of autism. Brain Pathol 17:434-447.

Paxinos G, Franklin KBJ (2001) The mouse brain in stereotaxic coordinates, Ed 2. San Diego: Academic.

Reinés A, Cereseto M, Ferrero A, Bonavita C, Wikinski S (2004) Neuronal cytoskeletal alterations in an experimental model of depression. Neuroscience 129:529-538.

Rivera RM, Stein P, Weaver JR, Mager J, Schultz RM, Bartolomei MS (2008) Manipulations of mouse embryos prior to implantation result in aberrant expression of imprinted genes on day 9.5 of development. Hum Mol Genet 17:1-14.

Seckl JR, Meaney MJ (2004) Glucocorticoid programming. Ann N Y Acad Sci 1032:63-84.

Steru L, Chermat R, Thierry B, Simon P (1985) The tail suspension test: a new method for screening antidepressants in mice. Psychopharmacology 85:367-370.

Tan H, Zhong P, Yan Z (2004) Corticotropin-releasing factor and acute stress prolongs serotonergic regulation of GABA transmission in prefrontal cortical pyramidal neurons. J Neurosci 24:5000-5008.

Teegarden SL, Bale TL (2007) Decreases in dietary preference produce increased emotionality and risk for dietary relapse. Biol Psychiatry 61:1021-1029.

Tsankova N, Renthal W, Kumar A, Nestler EJ (2007) Epigenetic regulation in psychiatric disorders. Nat Rev Neurosci 8:355-367.

Valentino RJ, Curtis AL (1991) Antidepressant interactions with corticotropin-releasing factor in the noradrenergic nucleus locus coeruleus. Psychopharmacol Bull 27:263-269.

Valentino RJ, Page ME, Curtis AL (1991) Activation of noradrenergic locus coeruleus neurons by hemodynamic stress is due to local release of corticotropin-releasing factor. Brain Res 555:25-34.

Walker E, Mittal V, Tessner K (2008) Stress and the hypothalamic pituitary adrenal axis activity in the developmental course of schizophrenia. Annu Rev Clin Psychol 4:189-216.

Wang H, Ogawa M, Wood JR, Bartolomei MS, Sammel MD, Kusanovic JP, Walsh SW, Romero R, Strauss JF 3rd (2008) Genetic and epigenetic mechanisms combine to control MMP1 expression and its association with preterm premature rupture of membranes. Hum Mol Genet 17:1087-1096.

Ward AJ (1991) Prenatal stress and childhood psychopathology. Child Psychiatry Hum Dev 22:97-110.

Watson JB, Mednick SA, Huttunen M, Wang X (1999) Prenatal teratogens and the development of adult mental illness. Dev Psychopathol 11:457-466.

Weatherly JN, Arthur EI (2006) Investigating retrospective influences on induction in rats' responding for $1 \%$ sucrose when food-pellet reinforcement is upcoming. J Gen Psychol 133:81-95.

Weaver IC, Diorio J, Seckl JR, Szyf M, Meaney MJ (2004a) Early environmental regulation of hippocampal glucocorticoid receptor gene expression: characterization of intracellular mediators and potential genomic target sites. Ann N Y Acad Sci 1024:182-212.

Weaver IC, Cervoni N, Champagne FA, D’Alessio AC, Sharma S, Seckl JR, Dymov S, Szyf M, Meaney MJ (2004b) Epigenetic programming by maternal behavior. Nat Neurosci 7:847-854.

Zwingman T, Erickson RP, Boyer T, Ao A (1993) Transcription of the sexdetermining region genes Sry and Zfy in the mouse preimplantation embryo. Proc Natl Acad Sci U S A 90:814-817. 